\title{
Characterization of colon cancer cells: a functional approach characterizing CD133 as a potential stem cell marker
}

Meike Schneider ${ }^{1,2^{*}}$, Johannes Huber ${ }^{1}$, Boris Hadaschik ${ }^{1}$, Gabrielle M Siegers ${ }^{3}$, Heinz-Herbert Fiebig ${ }^{2}$ and Julia Schüler ${ }^{2}$

\begin{abstract}
Background: Isolation and characterization of tumourigenic colon cancer initiating cells may help to develop novel diagnostic and therapeutic procedures.

Methods: We characterized a panel of fourteen human colon carcinoma cell lines and their corresponding xenografts for the surface expression of potential stem cell markers CD133, CD24, CD44, CDCP1 and CXCR4. In five cell lines and nine xenografts, mRNA expression of these markers was determined. Tumour growth behaviour of CD133+, CD133- and unsorted SW620 cells was evaluated in vivo.

Results: All five putative stem cell markers showed distinct expression patterns in the tumours examined. Two patient-derived cell lines highly expressed CD133 (> 85\% of positive cells) and three other cell lines had an expression level of about 50\% whereas in long-term culture based models CD133 expression ranged only from 0 to $20 \%$. In $8 / 14$ cell lines, more than $80 \%$ of the cells were positive for CD24 and 11/14 were over $70 \%$ positive for CD44. 10/14 cell lines expressed CDCP1 on $\geq 83 \%$ of cells. CXCR4 expression was determined solely on $94 \mathrm{~L}$ and SW480.

Analyses of the corresponding xenografts revealed a significant reduction of cell numbers expressing the investigated surface markers and showed single cell fractions expressing up to three markers simultaneously. Statistical analysis revealed that the CXCR4 mRNA level correlates negatively with the protein expression of CD133, CD44, CD24 and CDCP1 in cell lines and xenografts.

A lower differentiation grade of donor material correlated with a higher CDCP1 mRNA expression level in the respective tumour model.

In vivo growth behaviour studies of SW620 revealed significantly higher take rates and shorter doubling times in the tumour growth of CD133 positive subclones in comparison to the unsorted cell line or CD133 negative subclones.
\end{abstract}

Conclusions: Our data revealed correlations in the expression of surface markers CD44 and CD24 as well as CD44 and CDCP1 and strongly suggest that CD133 is a stem cell marker within our colon carcinoma panel. Further studies will elucidate its role as a potential therapeutic target.

Keywords: Stem cells, Colon cancer, CD133, Cancer stem cell like properties

\footnotetext{
* Correspondence: meike.schneider@med.uni-heidelberg.de

'Department of Urology, University of Heidelberg, Im Neuenheimer Feld 110,

D-69120 Heidelberg, Germany

Full list of author information is available at the end of the article
} 


\section{Background}

There is increasing evidence that the principles of stem cell biology are not only relevant for haematological malignancies but also for solid tumours. This concept includes the hypothesis that tumours consist of heterogeneous populations of cells differing in surface marker expression and growth capacities. Only a small subset of rare tumour stem cells is capable of initiating and propagating tumour formation. These special cells are also thought to initiate tumour metastasis and relapse after therapy [1,2]. A better characterization of tumour initiating cells could lead to improvement of cancer therapies.

In the past few years, subpopulations of cancer initiating cells have been isolated for haematological malignancies [3] as well as for solid tumours such as breast [4], pancreas [5], brain [6], and colon cancer $[7,8]$. The fundamental problem is to identify and separate tumour initiating cells from more differentiated tumour cells. For this purpose, cell surface antigens are used to characterize different cell populations.

CD133, CD44, CD24, CDCP1 and CXCR4 are five cell surface antigens whose expression is thought to indicate stem cell like properties. CD133 is a five-transmembrane domain antigen with a molecular weight of $120 \mathrm{kDa}$ [9] and is found on stem-like cells of various tissues and cancers like pancreatic, prostate, kidney and colorectal cancer [10].

CD44 is the major hyaluronan receptor and is important for the homing and settling of adult stem cells, metastasizing tumour cells and cancer initiating cells. Upregulated expression of CD44 increases tumour growth and has an anti-apoptotic effect [11].

The expression or lack of CD24 is a hallmark of a wide range of epithelial cancers like pancreatic, prostate or breast cancer $[4,11]$ and has also been used as an indicator for the likelihood of metastasis [12-14]. It may have important roles in migration and invasion by improving interactions between integrins and fibronectin [15].

Multiple SRC-family kinases (SFKs) are activated in carcinoma and appear to have an important role in metastasis and migration of tumour cells. CDCP1 [CUB (complement $\mathrm{C} 1 \mathrm{r} / \mathrm{C} 1 \mathrm{~s}$, Uegf, Bmp1) Domain-Containing Protein-1] is a transmembrane protein phosphorylated by SFKs, which enables the carcinoma cell to survive. This could be especially beneficial for a tumour stem cell $[16,17]$.

One of the major chemokine receptors expressed by cancer cells is CXCR4, the receptor for CXCL12 [stromal cell derived factor-1 (SDF-1)]. Organs such as the liver or lung produce SDF-1 and thereby increase the risk of developing metastasis by attracting circulating tumour cells [18] expressing CXCR4.
In a panel of colon cancer cell lines growing in 2D culture and as subcutaneous xenografts, we evaluated the expression of these five putative stem cell markers.

\section{Methods \\ Cell culture conditions}

The human colon carcinoma cell lines (CCL) HCT116, LOVO, HT29, SW620, DLD1, HCT15, SW480, COLO205, HCC2998, KM12, KM20LZ, and LS174T were obtained from the American Type Culture Collection (Rockville, MD). CCL $269 \mathrm{~L}$ and $94 \mathrm{~L}$ were established at Oncotest from colon carcinoma patients at the University Hospital/ University of Freiburg. All cells were grown in RPMI 1640 medium supplemented with $5 \%$ (vol/vol) fetal bovine serum, $1 \%(\mathrm{vol} / \mathrm{vol})$ penicillin $(100 \mathrm{U} / \mathrm{mL})$, streptomycin $(100 \mathrm{U} / \mathrm{mL}$ ), and $1 \%$ (vol/vol) L-glutamine (all from GIBCO-BRL, Grand Island, NY). Cells were maintained at $37^{\circ} \mathrm{C}$ and $5 \% \mathrm{CO}_{2}$. Media and supplement exchange were performed when $90 \%$ confluence was obtained.

\section{Antibodies}

Cell surface marker expression was determined using the following monoclonal antibodies: CD133/1 PE-conjugated mouse anti-human IgG1 (Miltenyi Biotech); CD44 FITCconjugated mouse anti-human IgG1 (Beckman Coulter); CDCP1 FITC-conjugated mouse anti-human IgG2b (MBL/Mobitec); CD24 PC5-conjugated mouse antihuman IgG1 (Beckman Coulter); and CXCR4 PE-Cy7conjugated mouse anti-human IgG2a,k (eBioscience). $5 \times$ $10^{6}$ cells were incubated with primary antibody or the corresponding isotype control, and the fluorescence intensity was determined by flow cytometry.

\section{Flow cytometry}

The percentage of positive tumour cells was assessed by measurement the fluorescence intensity of the abovementioned cell surface markers. All samples were analyzed on a FC500 flow cytometer (Beckman Coulter) which recorded 100,000-200,000 events per sample. The forward/side-scatter plots and propidium iodide $(1 \mathrm{mg} / \mathrm{ml}$, Roche) were used to gate out cell doublets and dead cells, respectively. Cell lines were independently analyzed four times and the mean value \pm standard deviation calculated. For the detection of cells expressing more than one antigen, CD133 positive cells were gated on and further analyzed for the expression of CD24 and CD44 or CDCP1 and CXCR4, respectively.

\section{Mice}

For the generation of tumour xenografts, 6-8 week old NMRI nude (NMRI nu/nu) mice were obtained from Charles River, Germany. For tumourigenicity experiments NOD. Cg-Prkdc ${ }^{\text {scid }}$ (NOD/SCID) mice were obtained from Taconic, Denmark. [The animals were housed in 
individually ventilated cages (IVC) set in air-conditioned rooms. The mice had free access to food and acidified water. According to the regulations for animal experiments, individual mice were sacrificed if tumour volume exceeded $1800 \mathrm{~mm}^{3}$ and/or body weight loss exceeded 15\%.] All animal experiments were conducted according to the rules of the German Protection of Animals Act (Tierschutzgesetz) and guidelines for the welfare and use of animals in cancer research [19].

\section{Generation of tumour xenografts}

To generate multiple identical xenografts, patientderived tumours were excised from a donor animal, cut into 4-5 mm diameter pieces and one piece per flank was implanted subcutaneously. Cell-line derived xenografts were induced by subcutaneous injection of $1 \times$ $10^{8}$ cells per flank into NMRI nu/nu mice.

\section{In vivo tumourigenecity experiments}

The colon cancer cell line SW620 was sorted for expression of CD133 on a MoFlo cell sorter (DakoCytomation). To obtain positive and negative populations, only the top $14 \%$ of brightly stained cells or the bottom $21 \%$ of dimly stained cells were selected. The unsorted SW620 cell line served as a control. $1 \times 10^{4}$ or $1 \times 10^{5}$ cells were injected subcutaneously into five NOD/SCID mice and monitored for their tumourigenecity. The resulting xenografts were analyzed for expression of the antigens by flow cytometry as described above. Tumours were measured either weekly or, for fast growing tumours, twice weekly and volumes were calculated according to the formula $\mathrm{a}^{*} \mathrm{~b}^{2} / 2$ where $\mathrm{a}$ is the longest diameter and $b$ the perpendicular axis. Group median relative tumour volumes were used for evaluation.

\section{Preparation of single-cell suspensions}

Xenografted tumours were mechanically minced with scissors and scalpels and subsequently incubated with an enzyme cocktail consisting of $41 \mathrm{U} / \mathrm{ml}$ collagenase (Sigma), $125 \mathrm{U} / \mathrm{ml}$ DNAse (Roche), and $100 \mathrm{U} / \mathrm{ml}$ hyaluronidase (Roche) at $37^{\circ} \mathrm{C}$ for approximately $45 \mathrm{~min}$. The cells were passed through stainless-steel sieves of $200 \mathrm{~mm}$ and $50 \mathrm{~mm}$ diameter mesh size and then washed. The percentage of viable cells was determined by trypan blue exclusion using a haemocytometer [20].

\section{Immunohistochemistry}

For immunohistochemical processing, sections were dewaxed and endogenous peroxide removed by incubation in $3 \% \mathrm{H}_{2} \mathrm{O}_{2}$. For antigen retrieval, the slides were incubated at $600 \mathrm{~W}$ in $10 \mathrm{mM}$ Tri-Sodium Citrate (dihydrate) $+0,05 \%$ Tween in distilled water $(\mathrm{pH} 6,0)$ for $20 \mathrm{~min}$. Unspecific binding sites were blocked by applying $5 \%$ NGS/1\%BSA in PBS for $60 \mathrm{~min}$ at room temperature, then a 1:70 dilution of the primary anti-CD133 antibody (Abcam Rabbit polyclonal to CD133 - N-terminal, ab71428) was added for $24 \mathrm{~h}$ at $4^{\circ} \mathrm{C}$. The Dako-Liquid DAB Substrate Chromogen System was used for further processing and visualization. The sections were counterstained with haematoxylin, dehydrated, and mounted.

\section{Tumour excision and RNA extraction}

For mRNA preparation, tumours were grown in untreated mice until they reached a size of $400-800 \mathrm{~mm}^{2}$. Following sacrifice, tumours were immediately excised, and tumour pieces free of necrosis were flash frozen in liquid nitrogen. Following mechanical tissue disruption, total tumour RNA was extracted using the RNeasy Mini kit (QIAGEN, Hilden, Germany). Prior to array analysis, one round of T7 promotor-based RNA amplification was performed [21].

\section{Microarrays, microarray data processing and normalization}

Affymetrix ${ }^{\circledR}$ HG-U133 Plus 2.0 mRNA expression arrays were used to determine the expression of 47,400 transcripts, corresponding to 38,500 human genes [22-27]. These arrays have been proven highly reproducible for mRNA expression analysis [23]. CEL result files were preprocessed using the gc-RMA [24] algorithm, after which each transcript was normalized using quantile normalization [25]. Microarray analysis was performed for a distinct colon cancer panel including 9 of the 11 xenografts evaluated for stem cell marker expression and 5 of the above mentioned cell lines. (see GEO nr. GSE35478, http://www. ncbi.nlm.nih.gov/geo/info/linking.html)

\section{Statistical analysis}

Statistical analysis of the co-expressed antigens was performed using the Spearman correlation coefficient $\left(\mathrm{r}_{\mathrm{S}}\right)$. The same analysis was applied to the correlation between mRNA and antigen expression. Correlation levels were defined as follows: $0.0<\mathrm{r}_{\mathrm{S}}<0.2$ : no correlation; $0.2<\mathrm{r}_{\mathrm{S}}<$ 0.5: weak to medium correlation; $0.5<\mathrm{r}_{\mathrm{S}}<0.8$ : distinct correlation and $0.8<\mathrm{r}_{\mathrm{S}}<1.0$ : strong correlation. For detection of statistically significant differences in the growth behaviour of single tumours, both a $t$-test and a one way analysis of variance was made (ANOVA) Using Sigma Stat Aspire Software (Ashburn).

\section{Results}

Distinct expression profile of five different surface markers in a colon carcinoma panel

All five surface markers showed differing expression patterns in the colon carcinoma panel. 11 of the 15 examined xenografts were cell-line derived and 4 were patientderived. For patient data characteristics of the colon carcinoma panel see Table 1. Each cell line or xenograft was evaluated in up to four independent experiments using 
flow cytometry. Results were highly reproducible, with standard deviations of $<10 \%$ within one model for a distinct surface marker.

Mean expression of CD133 on cell lines was $23.5 \pm$ $15.2 \%$ and $14.5 \pm 7.2 \%$ on xenografts (Figure 1). With respect to CD133 expression, the cell lines could be subdivided into four groups: five cell lines had a very small subpopulation of CD133 expressing cells $(\leq 0.02 \%)$; four cell lines expressed 8-15\% CD133; in CCL HT29, LOVO and SW620, 50\% of the cells expressed CD133; the highest CD133 expression levels were found on Oncotest proprietary cell lines $269 \mathrm{~L}$ and $94 \mathrm{~L}$ (85.5 and $85.8 \%$ respectively) (Figure 2). Examining the colon xenografts, four models revealed very weak $\mathrm{CD} 133$ expression ranging between 0 and $0.2 \%$. A group of six tumours expressed CD133 ranging from 4.0 to $14.5 \%$. Another five had expression levels of 20.7 to $36.6 \%$ (Figure 3 ).

Our analyses revealed a mean CD24 expression of $65 \pm$ $18.4 \%$ within the cell line and $7.1 \pm 7.6 \%$ within the xenograft panel (Figure 1). Three groups of cell lines emerged with respect to CD24 expression: 9/14 lines ranged between 76.8\% (DLD1) and 97.4\% (COLO205). In contrast, three had clearly weaker expression of less than $6 \%$. CCL HCT 15 and HCT116 were intermediate, with $35.2 \%$ and $58.1 \%$ CD24 positive cells (Figure 2). Xenografts CXF SW480 and CXF 1103 displayed CD24 expression $\leq$ $0.9 \%$. A group of 7 tumours expressed CD24 in a range of 3.3 to $16.9 \%$. A third group within the xenograft panel was characterized by CD24 expression $>24 \%$ with a maximum of $53.4 \%$ (Figure 3).
CD44 could be detected on all colon cancer cell lines investigated with a mean expression of $74.22 \pm 15.73 \%$. Xenografts revealed a mean expression of $3.9 \pm 4.9 \%$ (Figure 1). The majority of the colon cancer cell lines $(11 / 14)$ expressed CD44 on almost every cell (ranging 78.3\% to $97.6 \%)$. Exceptions were HCC2998, which displayed the lowest expression level (3.6\%) and SW620 and HCT 15 with $11.2 \%$ and $41.2 \%$ of CD 44 positive cells, respectively (Figure 2). Weaker CD44 expression was found within the xenograft panel; the highest expression was $32.8 \%$ and $35 \%$ on CXF LOVO and CXF LS174T, respectively. 5/15 models ranged between 6.3\% and $15.8 \%$, whereas the largest subgroup (eight tumour models) exhibited $<5 \%$ CD 44 expression (Figure 3).

CDCP1 was the most highly expressed marker detected on our cell line panel comprising $79.1 \pm 13.6 \%$ of positive cells. Xenografts expressed CDCP1 to $7.9 \pm 4.4 \%$ on the cell surface (Figure 1). Ten cell lines expressed between $86 \%$ and $98.5 \%$ CDCP1. On four cell lines, this surface marker was expressed on a lower percentage of cells $(<$ 64\%) (Figure 2). With respect to CDCP1 expression, the investigated xenografts could be subdivided into three groups: five models with $0.4 \%$ to $2.8 \%$ of positive cells; a group of four with expression levels between $6.3 \%$ and 9.9\%; and the six remaining tumours comprised $16.7 \%$ $32.7 \%$ CDCP1 positive cells (Figure 3 ).

CXCR4 showed very weak expression with a mean value of $1.14 \pm 3.6 \%$ and $0 \pm 1.3 \%$, respectively (Figure 1 ). The expression ranged between 0 and $0.2 \%$ despite CCL SW480 of which $23.5 \%$ were CXCR4 positive within the

Table 1 Patient data and characteristics of the examined colon carcinoma cell lines and xenografts

\begin{tabular}{|c|c|c|c|c|c|c|c|}
\hline \multirow[t]{2}{*}{ cell line } & \multicolumn{5}{|c|}{ Patient Data } & \multirow{2}{*}{$\begin{array}{c}\text { CEA secreting } \\
{\left[\mathrm{ng} / 10^{6} \text { cells }\right]}\end{array}$} & \multirow[t]{2}{*}{ source } \\
\hline & & differentiation & gender & age & Dukes Stage & & \\
\hline HTC116 & primary & poorly & male & 50 & n.k. & 1 & ATCC \\
\hline LOVO & metastasis & well & male & 56 & C & 908 & ATCC \\
\hline HT29 & primary & middle & female & 44 & n.k. & yes & $\mathrm{NCl}$ \\
\hline SW620 & metastasis & poorly & male & 51 & C & 0,15 & $\mathrm{NCl}$ \\
\hline DLD1 & primary & middle & male & 50 & C & 0,5 & $\mathrm{NCl}$ \\
\hline HCT15 & primary & middle & male & 50 & C & 5,4 & ATCC \\
\hline SW480 & primary & middle & male & 50 & B & 0,7 & $\mathrm{NCl}$ \\
\hline $269 \mathrm{~L}$ & primary & poorly & male & 56 & C & n.k. & Oncotest \\
\hline $94 \mathrm{~L}$ & primary & middle & male & 70 & n.k. & n.k. & Oncotest \\
\hline COLO205 & metastasis & poorly & male & 70 & D & 4,1 & $\mathrm{NCl}$ \\
\hline HCC2998 & primary & well & n.k. & n.k. & n.k. & n.k. & $\mathrm{NCl}$ \\
\hline KM12 & primary & poorly & n.k. & n.k. & B & n.k. & $\mathrm{NCl}$ \\
\hline KM2O & primary & poorly & n.k. & n.k. & D & n.k. & $\mathrm{NCl}$ \\
\hline LS174T & primary & middle & female & 58 & B & 1994 & ATCC \\
\hline CXF 269 & primary & poorly & male & 56 & C & n.k. & Oncotest \\
\hline CXF 243 & primary & poorly & male & 45 & n.k. & n.k. & Oncotest \\
\hline CXF 280 & metastasis & poorly & female & 56 & n.k. & n.k. & Oncotest \\
\hline CXF 1103 & primary & poorly & male & 56 & n.k. & n.k. & Oncotest \\
\hline
\end{tabular}

n.k. not known 


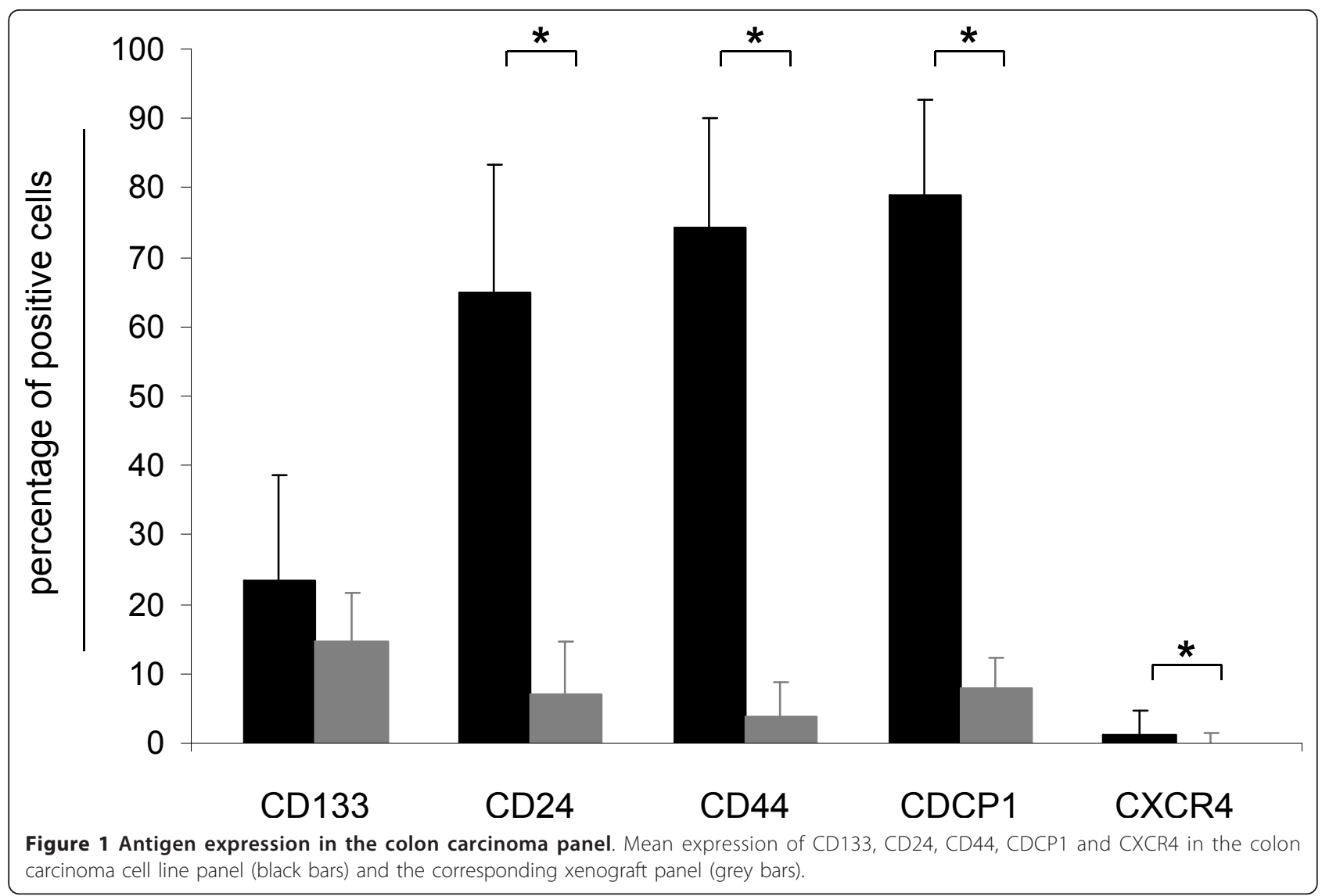

cell line panel (Figure 2). CXF LOVO was the only xenograft for which more than $1 \%$ CXCR4 positive cells could be identified (Figure 3).

Statistical analyses revealed no correlations among the investigated surface markers within the cell line panel. However, within the xenograft panel CD24 and CD44 expression correlated distinctly (spearman correlation, $\mathrm{r}_{\mathrm{s}}=$ 0.59 , $\mathrm{p}<0.001$ ) as did CD44 and CDCP1 protein expression (spearman correlation, $\mathrm{r}_{\mathrm{s}}=0.673, \mathrm{p}<0.001$ ).

Surface marker expression was downregulated in the majority of corresponding xenografts. For CD24, CD44, CDCP1 and CXCR4, the difference in expression level was statistically significant ( $t$-test, $\mathrm{p}<0.001, \mathrm{p}<0.019$; Figure 1 ). Despite these significant reduction, CD133 expression was up-regulated when KM20 and KM12 tumour cells grew subcutaneously in nude mice. (KM20: 6.6-10.6\%; KM12: 9.1-14.9\%).

CD133 positive subpopulation of the xenograft panel included small fractions of double and triple positive cells The CD133 positive subpopulations within the xenograft panel were further analysed for parallel expression of CD44 and CD24 or CDCP1. Most cells (83.4\%) expressed CD133 exclusively on their cell surface. A mean percentage of 3.03 was triple positive (CD133/CD24/CD44).
1.71\% (CD133/CD44) and 3.09\% (CD133/CD24) were double positive, respectively. $4.2 \%$ expressed CD133 and CDCP1 simultaneously (Figure 4).

CXCR4 mRNA level correlates negatively with protein expression of the other four surface markers

Additional statistical analyses were performed to study the correlation of protein expression (measured by flow cytometry), mRNA expression (measured by gene expression profiling) and patient data within the colon carcinoma panel.

On the mRNA level, CXCR4 expression correlated negatively with protein levels of CD133 and CD24 in cell lines as well as CDCP1 in cell lines and xenografts (Table 2).

Another statistically significant correlation could be found between tumour differentiation in the donor patient and the mRNA expression of CDCP1 (spearman correlation, $r_{s}=0.722, p=0.007$ ) in the respective cell line: lower differentiation grade of donor material correlated with higher CDCP1 expression at the mRNA level (Table 2).

CD133-positive and negative SW620 cells exhibit differing growth capacities in vivo

In vivo tumourigeneicity experiments revealed that CD133 expressing SW620 cells were more tumourigenic 


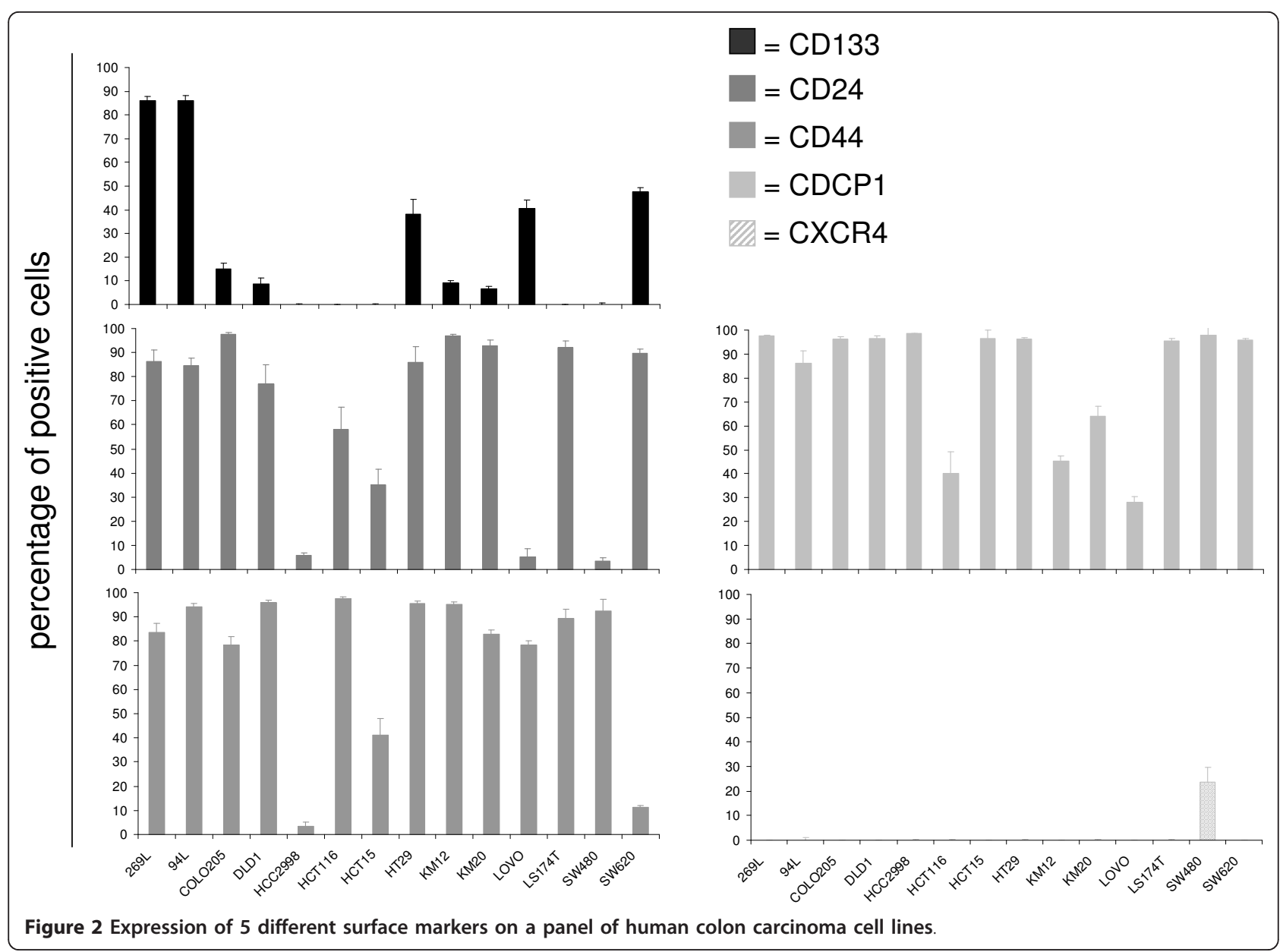

than cells that did not express this cell surface marker. CD133 positive subclones showed significantly higher take rates, as well as shorter doubling and induction times than the unsorted cell line or CD133 negative cells, respectively. At least $1 \times 10^{5}$ tumour cells were needed for tumour formation as injection of $1 \times 10^{4}$ SW620 cells induced no xenograft formation within 89 observation days, independent of CD133 surface expression. $1 \times 10^{5} \mathrm{CD} 133$ positive cells induced tumours in all five injected mice within 39 days of tumour cell inoculation. In contrast, in groups receiving either unsorted or CD133 negative cells, tumours occurred later (42 days post-injection) and only in $60 \%$ of mice.

Calliper measurements revealed a median tumour volume of $572 \mathrm{~mm}^{3} 46$ days after tumour cell injection in the CD133 positive group. This was significantly higher than median tumour volumes of xenografts derived from CD133 negative or unsorted SW620 cells (98.7 and $93.2 \mathrm{~mm}^{3}$, respectively, $\mathrm{p}<0.001$ ). Thus, the higher tumourigenic potential of CD133 expressing cells was confirmed by these data. No difference in growth behaviour could be determined comparing CD133 negative subclones and the unsorted cell line (Figure 5).
Xenografts from this tumourigenicity experiment were analyzed for expression of CD133 by immunohistochemical staining. No significant difference in the expression profile of this antigen could be shown for different SW620 cell populations (derived from initially CD133+/-/unsorted cells, Figure 6).

\section{Discussion}

A basic problem in cancer research is identifying the cells responsible for tumour formation. Within the cancer stem cell model, there is a small subset of cells capable of initiating and sustaining growth of a neoplastic clone. Tumour stem cells are probably long-lived cells that accumulate cancer-inducing mutations. Furthermore, they have the unique ability to self-renew and, through differentiation, to generate mature non-tumourigenic cancer cells of all lineages. These mature cells appear to constitute the bulk of cancer cells within a tumour.

If the cancer stem cell hypothesis is correct, we have to reconsider treatment regimens that eradicate the bulk of cancer cells, but may not target the cell of origin. These cells are thought to be refractory to classical chemotherapy and responsible for metastasis and relapse. Further 


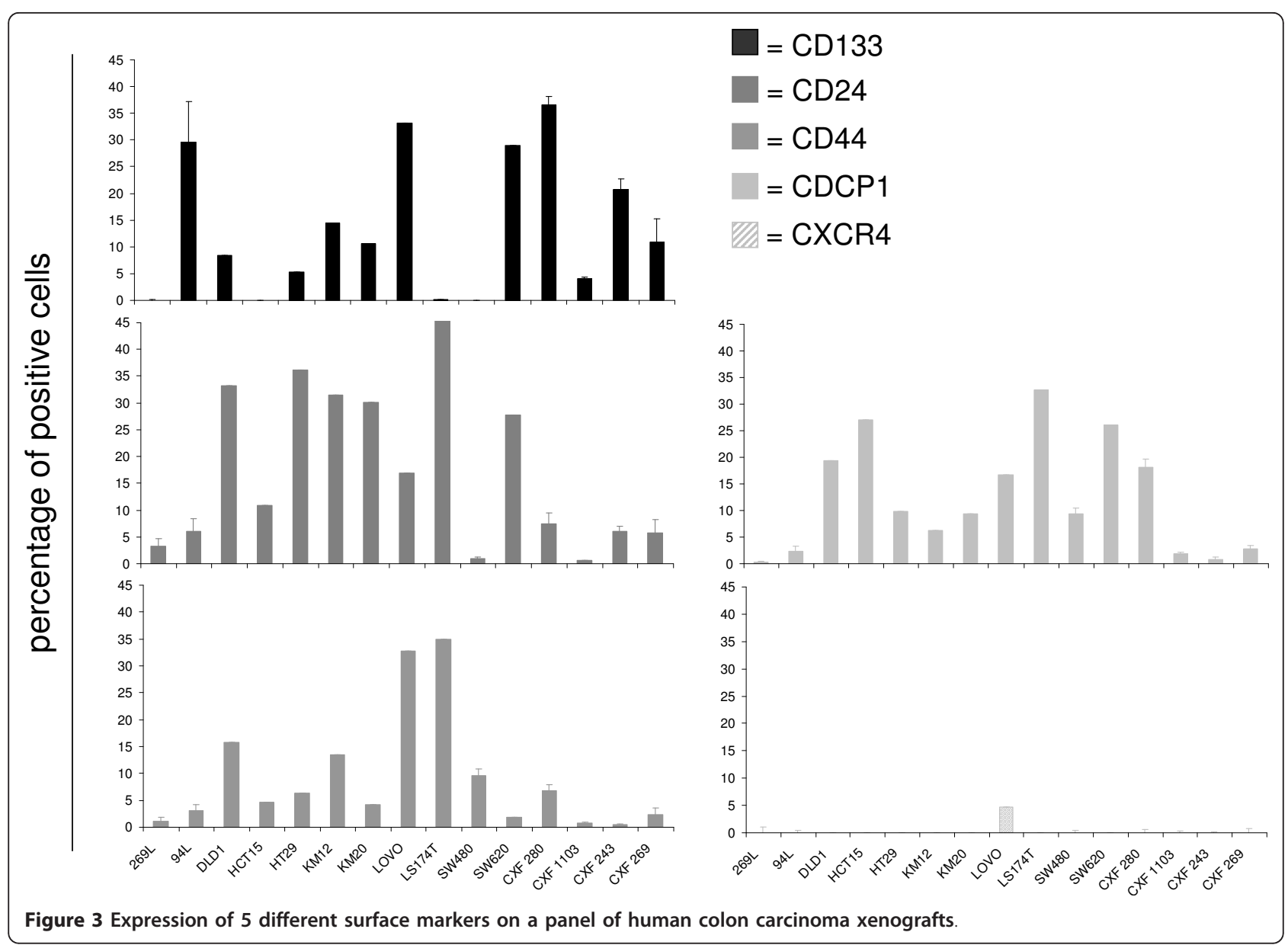

characterization of the stem cell population is required to identify potential targets for prospective therapies [26,27].

With this study, we are the first to characterize a large panel of colon carcinoma cell lines and their corresponding xenografts for simultaneous expression of several stem cell markers and thereby identify different cell fractions.

The cell surface antigens examined showed a distinct expression pattern within both colon carcinoma cell line and xenograft panels such that different cell fractions could be distinguished. In general, the cell lines expressed CD133, CD44, CD24, CDCP1 and CXCR4 at higher levels than the xenografts. The cancer stem cell hypothesis suggests that the heterogeneity in a tumour results from ongoing differentiation and the majority of tumour cells lose their proliferative potential during this process of maturation $[1,28]$. This could be a reason why the antigens are expressed at a lower level in vivo.

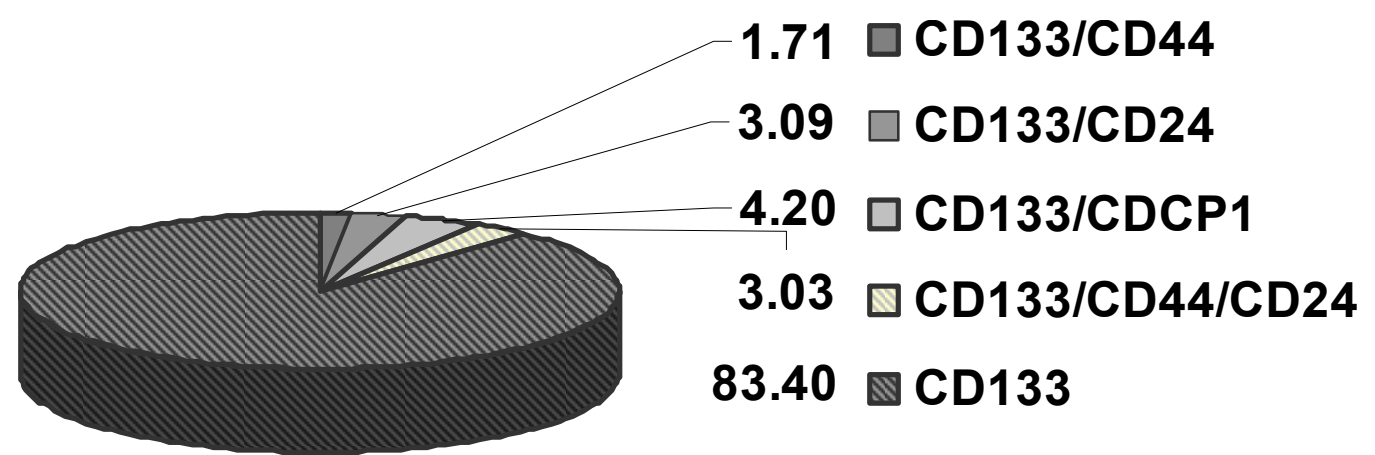

Figure 4 Mean percentage of double- and triple-positive cells within the CD133+ subpopulation of xenografts. 
Table 2 Correlations between different antigens and clinical data

\begin{tabular}{|c|c|c|c|c|c|c|c|c|}
\hline & $\begin{array}{c}\mathrm{CCL} \text { CD133 } \\
\text { protein }\end{array}$ & $\begin{array}{c}\mathrm{CCL} C D 24 \\
\text { protein }\end{array}$ & $\begin{array}{c}\text { CCL CD44 } \\
\text { protein }\end{array}$ & $\begin{array}{l}\text { CCL CDCP1 } \\
\text { protein }\end{array}$ & $\begin{array}{l}\text { CXF CDCP1 } \\
\text { protein }\end{array}$ & $\begin{array}{l}\text { Patient tumour } \\
\text { differentiation }\end{array}$ & $\begin{array}{l}\text { Patient } \\
\text { age }\end{array}$ & \\
\hline \multirow[t]{2}{*}{$\begin{array}{l}\text { CCL CD24 gene } \\
\text { expression }\end{array}$} & & & & & & & $-0,671$ & $\begin{array}{l}\text { spearman correl. } \\
\text { Coefficient }\end{array}$ \\
\hline & & & & & & & 0,00575 & $p$-value \\
\hline \multirow[t]{2}{*}{$\begin{array}{l}C C L \text { CDCP1 gene } \\
\text { expression }\end{array}$} & & & & & & 0,722 & & $\begin{array}{l}\text { spearman correl. } \\
\text { Coefficient }\end{array}$ \\
\hline & & & & & & 0,00707 & & $p$-value \\
\hline \multirow[t]{2}{*}{$\begin{array}{l}\text { CLL CXCR4 gene } \\
\text { expression }\end{array}$} & $-0,671$ & $-0,615$ & 0,692 & $-0,622$ & $-0,627$ & & & $\begin{array}{l}\text { spearman correl. } \\
\text { Coefficient }\end{array}$ \\
\hline & 0,0154 & 0,0308 & 0,0113 & 0,0285 & 0,0263 & & & p-value \\
\hline
\end{tabular}

Correlation of protein expression (measured by flow-cytometry), mRNA expression (measured by gene expression profiling) and patient data within the colon carcinoma panel

During xenograft development, tumour cells lose their stem cell characteristics and also distinct cell surface antigens. It is already well known for haematological malignancies like multiple myeloma, acute myeloid leukaemia or acute lymphocytic leukaemia that differentiation is driven by cell surface antigens [29]. Aside from differentiation, lower expression of these surface markers might be explained by the influence of the tumour microenvironment. Tumour cells growing subcutaneously in nude mice are exposed to a completely different environment than tumour cells in vitro. It is possible that expression of these antigens would have been different if transplanted orthotopically, as it is unclear whether xenotransplantation accurately reflects

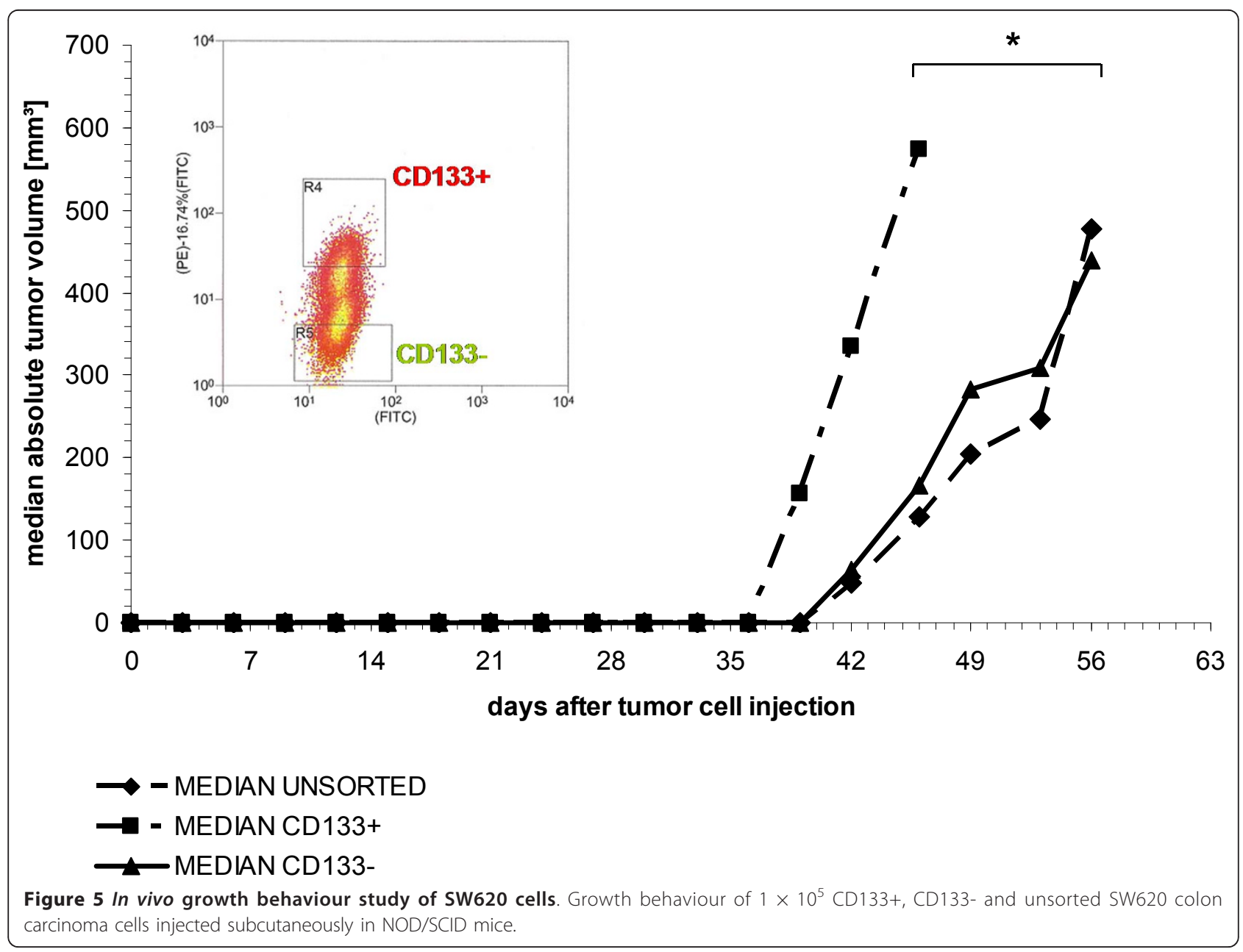



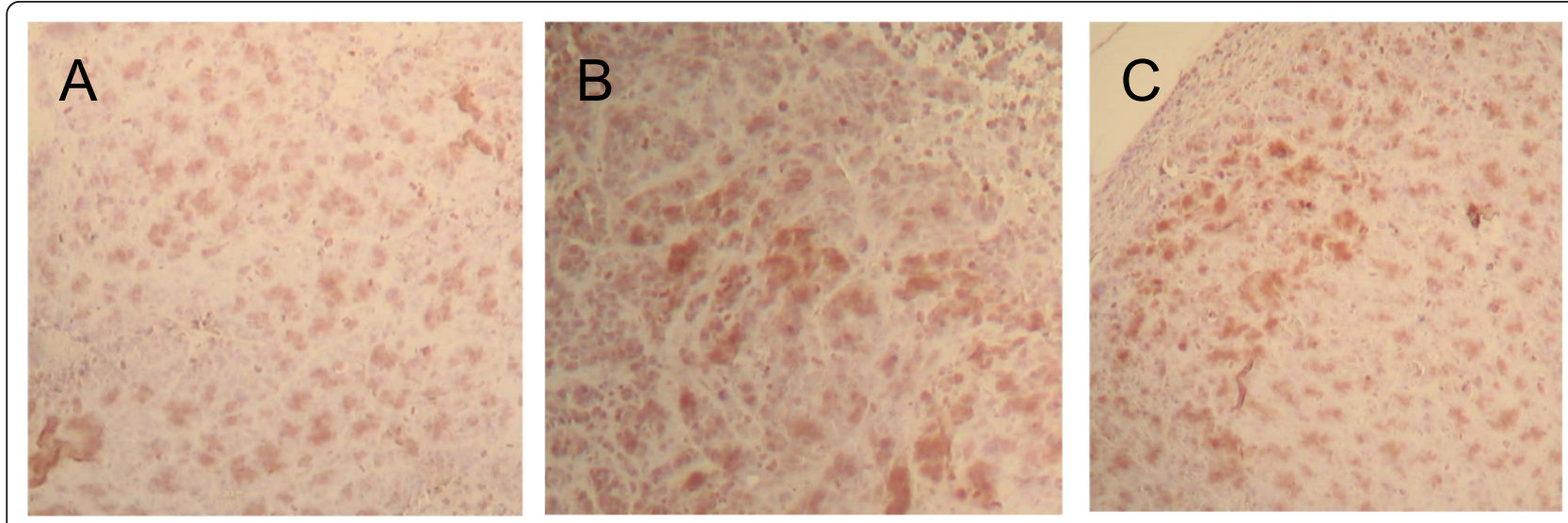

Figure 6 Immunohistochemistry (IHC) of different SW620 cell fractions. CD133 expression in xenografts that grew out of unsorted, CD133+ and CD133- subclones of SW620 colon carcinoma cells. A: IHC $\alpha$-hu CD133: SW620 unsorted cells injected subcutaneously (SC) in NOD/SCID mice. B: IHC $\alpha$-hu CD133: SW620 CD133+ cells injected sc in NOD/SCID mice. C: IHC $\alpha$-hu CD133: SW620 CD133- cells injected sC in NOD/SCID mice.

human stem cell biology or whether the transplanted cells are human cancer cells that have adapted to the mouse environment [30]. The appropriate microenvironment is essential for maintenance of "stemness" as has been shown for hematopoietic stem cells [31], brain tumour stem cells [32] and, more recently, colon cancer stem cells. Vermeulen et al. showed that factors secreted by myofibroblasts also restore the cancer stem cell phenotype in more differentiated colon carcinoma cells. Thus, it appears that "stemness" of colon carcinoma cells is a dynamic quality that can be influenced by the microenvironment [33]. On the other hand, one could also argue that in vitro culture conditions select for the maintenance of stem cell properties. In our experiments, we could show that colon cancer cells show very different phenotypes in vitro versus in vivo, thus suggesting a close relationship between the microenvironment and the existence of different cell types. This knowledge is also crucial for testing new drugs under in vitro versus in vivo conditions. [Of note, the procedure for preparing single cell suspensions from the xenografts had no statistically relevant influence on antigen expression (see Additional file 1: Figure S7).]

It is not yet known to what extent single antigens are responsible for stem cell maintenance, thus we do not know the functional relevance of these cell surface markers. CD133-expressing colon cancer cells produce interleukin 4 (IL-4) as an autocrine growth factor. IL-4 promotes the induction of anti-apoptotic genes, thus promoting cell survival. Administration of a neutralizing IL-4 antibody improved the efficacy of conventional chemotherapy [34]. These data suggest that elimination of CD133-expressing cells could prove beneficial in the treatment of colorectal carcinoma. Others have described the more tumourigenic capacity of CD133-expressing cells compared to cells that do not express this antigen $[7,8]$. Also, different Wnt factors affect proliferation and differentiation in CD133expressing cells [35]. The Wnt signalling cascade has emerged as an important regulator of normal and malignant stem cells in intestinal, hematopoietic and epidermal systems [36]. Since CD133 has thus been characterized as a putative stem cell marker, we aimed to further clarify its exact role via additional functional analysis.

Our data show that CD133 is not expressed by every colorectal tumour cell. In our experiments, tumours that grew out of a CD133-expressing cell population showed enhanced growth behaviour compared to the control group. We could not, however, clearly identify the role of CD133 in this process. Maybe this marker is crucial for the development of the tumour. Alternatively, perhaps it is a marker that does not initiate but rather enhances tumour growth, for example, by means of better tumour vascularization. CD133-expressing progenitor cells in the kidney contributed to better tumour vascularization by differentiating into endothelial cells [37]. Beier et al. demonstrated that glioblastoma cancer stem cells can be either CD133+ or CD133-, suggesting that this marker is not limiting for "stemness" [38]. This fits with our results indicating that tumours also grew out of CD133-negative cells. CD133 knock down experiments would be useful to further explore the functional relevance of this cell surface marker.

CXCR4 is said to play a key role in tumour progression and metastasis in colon cancer [39]. In our study, the mean CXCR4 expression within the xenograft panel was $0.85 \%$ with notable expression of $>1 \%$ in one of fifteen models. Expression may have been upregulated had cells been injected in a more appropriate microenvironment, e.g., via orthotopic implantation $[40,41]$.

Our study is limited in that the relationship between cell surface antigens and cell properties, like growth 
behaviour, remains to be further elucidated. In haematological malignancies, identification of cells with different growth capacities is based on cell surface antigens and these exhibit functional heterogeneity [42]. Flow cytometry is a widespread and reliable method to detect antigens on single cells [43]. We analyzed cell surface antigens on single cell suspensions derived from xenografted tumours from our colon carcinoma cell line panel. Our studies revealed that some xenograft cells express more than one of the five surface markers we studied and significant correlations between different markers emerged. CDCP1 is highly expressed in lung and colon cancers, where it is phosphorylated by Src family kinases and involved in anchorage independence of cancer cells $[16,44]$. These properties are important for tumour progression and metastasis. The correlation we observed between CDCP1 expression and disease stage of donor patients is in line with the results of Uekita et al. who described a correlation between expression and phosphorylation levels of CDCP1 with the invasive potential of scirrhous gastric cancers [45]. These data point to the relevance of this marker as a potential therapeutic target for modulating cancer metastasis.

In addition to correlations between markers and clinical parameters, we found small subsets of double- and triple-positive cells in our colon cancer panel which could comprise a stem cell population and should be analyzed in more detail.

\section{Conclusions}

Our study characterized a large panel of colon carcinoma cell lines and their corresponding xenografts, showing significantly reduced expression of the cell surface markers CD133, CD44, CD24, CDCP1 and CXCR4 in vivo. A small subset of CD133-positive colon carcinoma cells additionally expressed CD24, CD44 or CDCP1, so that a correlation in antigen expression can be assumed. In vivo growth kinetics provide strong evidence that CD133 plays an important role [within the mentioned surface marker profile]. Further studies will show the functional relevance of these markers in colon carcinomas and assess their potential as therapeutic targets in oncology.

\section{Ethics committee approval}

We performed all actions according to the "Declaration of Helsinki" in its latest version and respected usual data protection requirements.

\section{Additional material}

Additional file 1: Figure S7 Expression of five different surface markers on untreated (solid bars) and enzymatically pretreated (shaded bars) colon cancer cell lines $269 \mathrm{~L}$ and $94 \mathrm{~L}$.

\section{Acknowledgements}

We thank the department of Prof. Mertelsmann for their technical support with the in vivo growth experiments and gratefully acknowledge Prof. Stefan Duensing for critical reading of this manuscript.

\section{Author details}

'Department of Urology, University of Heidelberg, Im Neuenheimer Feld 110, D-69120 Heidelberg, Germany. ${ }^{2}$ Oncotest GmbH - Institute for Experimental Oncology, Am Flughafen 12-14, D-79108 Freiburg, Germany. ${ }^{3}$ Imaging Research Labs, Robarts Research Institute, The University of Western Ontario, London, ON N6A 5K8, Canada.

\section{Authors' contributions}

MS performed most of the experimental work and wrote the first draft of the manuscript and all authors have contributed to, read and approved the final version of the manuscript.

\section{Competing interests}

The authors declare that they have no competing interests.

Received: 13 August 2011 Accepted: 20 March 2012

Published: 20 March 2012

\section{References}

1. Dalerba P, Cho RW, Clarke MF: Cancer stem cells: models and concepts. Annu Rev Med 2007, 58:267-284.

2. Steeg PS: Tumor metastasis: mechanistic insights and clinical challenges. Nat Med 2006, 12(8):895-904.

3. Wang JC, Dick JE: Cancer stem cells: lessons from leukemia. Trends Cell Biol 2005, 15(9):494-501.

4. Al-Hajj M, Wicha MS, Benito-Hernandez A, Morrison SJ, Clarke MF: Prospective identification of tumorigenic breast cancer cells. Proc Natl Acad Sci USA 2003, 100(7):3983-3988.

5. Li C, Heidt DG, Dalerba P, Burant CF, Zhang L, Adsay V, Wicha M, Clarke MF, Simeone DM: Identification of pancreatic cancer stem cells. Cancer Res 2007, 67(3):1030-1037.

6. Singh SK, Hawkins C, Clarke ID, Squire JA, Bayani J, Hide T, Henkelman RM Cusimano MD, Dirks PB: Identification of human brain tumour initiating cells. Nature 2004, 432(7015):396-401.

7. O'Brien CA, Pollett A, Gallinger S, Dick JE: A human colon cancer cell capable of initiating tumour growth in immunodeficient mice. Nature 2007, 445(7123):106-110

8. Ricci-Vitiani L, Lombardi DG, Pilozzi E, Biffoni M, Todaro M, Peschle C, De Maria R: Identification and expansion of human colon-cancer-initiating cells. Nature 2007, 445(7123):111-115.

9. Miraglia S, Godfrey W, Yin AH, Atkins K, Warnke R, Holden JT, Bray RA, Waller EK, Buck DW: A novel five-transmembrane hematopoietic stem cell antigen: isolation, characterization, and molecular cloning. Blood 1997, 90(12):5013-5021.

10. Mizrak D, Brittan M, Alison MR: CD133: molecule of the moment. J Pathol 2008, 214(1):3-9

11. Keysar SB, Jimeno $A$ : More than markers: biological significance of cancer stem cell-defining molecules. Mol Cancer Ther 2010, 9(9):2450-2457.

12. Lim SC: CD24 and human carcinoma: tumor biological aspects. Biomed Pharmacother 2005, 59(Suppl 2):S351-S354.

13. Sano A, Kato H, Sakurai S, Sakai M, Tanaka N, Inose T, Saito K, Sohda M, Nakajima M, Nakajima T, et al: CD24 expression is a novel prognostic factor in esophageal squamous cell carcinoma. Ann Surg Oncol 2009, 16(2):506-514

14. Aigner $\mathrm{S}$, Sthoeger ZM, Fogel M, Weber E, Zarn J, Ruppert M, Zeller $\mathrm{Y}$, Vestweber D, Stahel R, Sammar M, et al: CD24, a mucin-type glycoprotein, is a ligand for P-selectin on human tumor cells. Blood 1997, 89(9):3385-3395

15. Baumann P, Cremers N, Kroese F, Orend G, Chiquet-Ehrismann R, Uede T, Yagita H, Sleeman JP: CD24 expression causes the acquisition of multiple cellular properties associated with tumor growth and metastasis. Cancer Res 2005, 65(23):10783-10793.

16. Uekita T, Jia L, Narisawa-Saito M, Yokota J, Kiyono T, Sakai R: CUB domaincontaining protein 1 is a novel regulator of anoikis resistance in lung adenocarcinoma. Mol Cell Biol 2007, 27(21):7649-7660. 
17. Benes CH, Poulogiannis G, Cantley LC, Soltoff SP: The SRC-associated protein CUB Domain-Containing Protein-1 regulates adhesion and motility. Oncogene 2012

18. Kucia M, Reca R, Miekus K, Wanzeck J, Wojakowski W, JanowskaWieczorek A, Ratajczak J, Ratajczak MZ: Trafficking of normal stem cells and metastasis of cancer stem cells involve similar mechanisms: pivotal role of the SDF-1-CXCR4 axis. Stem cells (Dayton, Ohio) 2005, 23(7):879-894.

19. Workman P, Aboagye EO, Balkwill F, Balmain A, Bruder G, Chaplin DJ, Double JA, Everitt J, Farningham DA, Glennie MJ, et al: Guidelines for the welfare and use of animals in cancer research. $\mathrm{Br} J$ Cancer 2010, 102(11):1555-1577.

20. Fiebig HH, Maier A, Burger AM: Clonogenic assay with established human tumour xenografts: correlation of in vitro to in vivo activity as a basis for anticancer drug discovery. Eur J Cancer 2004, 40(6):802-820.

21. Fiebig HH, Schuler J, Bausch N, Hofmann M, Metz T, Korrat A: Gene signatures developed from patient tumor explants grown in nude mice to predict tumor response to 11 cytotoxic drugs. CANCER GENOMICS PROTEOMICS 2007, 4(3):197-209.

22. Affymetrix Database. [http://www.affymetrix.com/support/technical/ datasheets/human_datasheet.pdf]

23. Shi L, Reid LH, Jones WD, Shippy R, Warrington JA, Baker SC, Collins PJ, de Longueville F, Kawasaki ES, Lee KY, et al: The MicroArray Quality Control (MAQC) project shows inter- and intraplatform reproducibility of gene expression measurements. Nat Biotechnol 2006, 24(9):1151-1161.

24. Zhijin Wu, Rafael Al, Gentleman Robert, Murillo Francisco Martinez, Spencer Forrest: A Model Based Background Adjustment for Oligonucleotide Expression Arrays. Johns Hopkins University, Department of Biostatistics Working Papers; 2004, Working Paper 1.

25. Bengtsson H, Ray A, Spellman P, Speed TP: A single-sample method for normalizing and combining full-resolution copy numbers from multiple platforms, labs and analysis methods. Bioinformatics (Oxford, England) 2009, 25(7):861-867.

26. Clarke MF, Dick JE, Dirks PB, Eaves CJ, Jamieson CH, Jones DL, Visvader J, Weissman IL, Wahl GM: Cancer stem cells-perspectives on current status and future directions: AACR Workshop on cancer stem cells. Cancer Res 2006, 66(19):9339-9344.

27. Reya T, Morrison SJ, Clarke MF, Weissman IL: Stem cells, cancer, and cancer stem cells. Nature 2001, 414(6859):105-111.

28. Vermeulen L, Sprick MR, Kemper K, Stassi G, Medema JP: Cancer stem cellsold concepts, new insights. Cell Death Differ 2008, 15(6):947-958.

29. Matsui W, Wang Q, Barber JP, Brennan S, Smith BD, Borrello I, McNiece I, Lin $L$, Ambinder RF, Peacock $C$, et al: Clonogenic multiple myeloma progenitors, stem cell properties, and drug resistance. Cancer Res 2008, 68(1):190-197.

30. Kelly PN, Dakic A, Adams JM, Nutt SL, Strasser A: Tumor growth need not be driven by rare cancer stem cells. Science (New York, NY) 2007, 317(5836):337

31. Li L, Xie T: Stem cell niche: structure and function. Annu Rev Cell Dev Biol 2005, 21:605-631.

32. Calabrese C, Poppleton H, Kocak M, Hogg TL, Fuller C, Hamner B, Oh EY, Gaber MW, Finklestein D, Allen $M$, et al: A perivascular niche for brain tumor stem cells. Cancer Cell 2007, 11(1):69-82.

33. Vermeulen L, De Sousa EMF, van der Heijden M, Cameron K, de Jong JH, Borovski T, Tuynman JB, Todaro M, Merz C, Rodermond H, et al: Wnt activity defines colon cancer stem cells and is regulated by the microenvironment. Nat Cell Biol 2003, 12(5):468-476.

34. Todaro M, Alea MP, Di Stefano AB, Cammareri P, Vermeulen L, lovino F, Tripodo C, Russo A, Gulotta G, Medema JP, et al: Colon cancer stem cells dictate tumor growth and resist cell death by production of interleukin4. Cell Stem Cell 2007, 1(4):389-402.

35. Nikolova T, Wu M, Brumbarov K, Alt R, Opitz H, Boheler KR, Cross M, Wobus AM: WNT-conditioned media differentially affect the proliferation and differentiation of cord blood-derived CD133+ cells in vitro. Differentiation; research in biological diversity 2007, 75(2):100-111.

36. Reya T, Clevers H: Wnt signalling in stem cells and cancer. Nature 2005, 434(7035):843-850

37. Bruno S, Bussolati B, Grange C, Collino F, Graziano ME, Ferrando U, Camussi G: CD133+ renal progenitor cells contribute to tumor angiogenesis. Am J Pathol 2006, 169(6):2223-2235.

38. Beier D, Hau P, Proescholdt M, Lohmeier A, Wischhusen J, Oefner PJ, Aigner L, Brawanski A, Bogdahn U, Beier CP: CD133(+) and CD133(-) glioblastoma-derived cancer stem cells show differential growth characteristics and molecular profiles. Cancer Res 2007, 67(9):4010-4015.

39. Kim J, Takeuchi H, Lam ST, Turner RR, Wang HJ, Kuo C, Foshag L, Bilchik AJ, Hoon DS: Chemokine receptor CXCR4 expression in colorectal cancer patients increases the risk for recurrence and for poor survival. $J$ Clin Oncol 2005, 23(12):2744-2753.

40. Yang M, Reynoso J, Bouvet M, Hoffman RM: A transgenic red fluorescent protein-expressing nude mouse for color-coded imaging of the tumor microenvironment. J Cell Biochem 2009, 106(2):279-284.

41. Matsusue R, Kubo H, Hisamori S, Okoshi K, Takagi H, Hida K, Nakano K, Itami A, Kawada K, Nagayama S, et al: Hepatic stellate cells promote liver metastasis of colon cancer cells by the action of SDF-1/CXCR4 axis. Ann Surg Oncol 2009, 16(9):2645-2653.

42. Fialkow PJ, Singer JW, Raskind WH, Adamson JW, Jacobson RJ, Bernstein ID, Dow LW, Najfeld V, Veith R: Clonal development, stem-cell differentiation, and clinical remissions in acute nonlymphocytic leukemia. N Engl J Med 1987, 317(8):468-473.

43. Xie W, Wang X, Du W, Liu W, Qin X, Huang S: Detection of molecular targets on the surface of CD34+CD38- bone marrow cells in myelodysplastic syndromes. Cytometry A 2010, 77(9):840-848.

44. Scherl-Mostageer M, Sommergruber W, Abseher R, Hauptmann R, Ambros P, Schweifer N: Identification of a novel gene, CDCP1, overexpressed in human colorectal cancer. Oncogene 2001, 20(32):4402-4408.

45. Uekita T, Tanaka M, Takigahira M, Miyazawa Y, Nakanishi Y, Kanai Y, Yanagihara K, Sakai R: CUB-domain-containing protein 1 regulates peritoneal dissemination of gastric scirrhous carcinoma. Am J Pathol 2008, 172(6):1729-1739.

\section{Pre-publication history}

The pre-publication history for this paper can be accessed here: http://www.biomedcentral.com/1471-2407/12/96/prepub

\section{doi:10.1186/1471-2407-12-96}

Cite this article as: Schneider et al:: Characterization of colon cancer cells: a functional approach characterizing CD133 as a potential stem cell marker. BMC Cancer 2012 12:96.

\section{Submit your next manuscript to BioMed Central and take full advantage of:}

- Convenient online submission

- Thorough peer review

- No space constraints or color figure charges

- Immediate publication on acceptance

- Inclusion in PubMed, CAS, Scopus and Google Scholar

- Research which is freely available for redistribution 